\title{
DEVELOPMENT OF NEW DISSOLUTION TEST AND HPLC-RP METHOD FOR ANTI-PARASITIC ORNIDAZOLE COATED TABLETS
}

\author{
Mônica Felts de La Roca Soares e José Lamartine Soares Sobrinho \\ Departamento de Bioquímica e Farmacologia, Universidade Federal do Piauí, Campus Universitário Ministro Petrônio Portella, \\ 64049-550 Teresina - PI, Brasil \\ Severino Grangeiro Júnior, Keyla Emanuelle Ramos da Silva, Lariza Darlene Santos Alves e Pedro José Rolim Neto* \\ Departamento de Ciências Farmacêuticas, Universidade Federal de Pernambuco, Rua Arthur de Sá, s/n, 50740-521 Recife - PE, Brasil
}

Recebido em 14/5/09; aceito em 7/7/09; publicado na web em 8/1/10

\begin{abstract}
This work aimed the development and validation of a new dissolution test for ornidazole coated tablets. The dissolution conditions were determined after testing Sink conditions, dissolution medium, apparatus, stirring speed, $24 \mathrm{~h}$ stability and medium filtration influence. The best conditions were paddle at a stirring speed of $75 \mathrm{rpm}$ and $900 \mathrm{~mL}$ of $0.1 \mathrm{M} \mathrm{HCl}$. A new HPLC quantification method was developed and validated. The dissolution test and quantification method showed to be adequate for their purposes and could be applied for quality control of ornidazole coated tablets, since there is no official monograph.
\end{abstract}

Keywords: ornidazole; quality control; dissolution test.

\section{INTRODUCTION}

Ornidazole [1-(2-hydroxy-3-chloropropyl)-2-methyl-5-nitroimidazole], a synthetic derivative of 5-nitroimidazoles (Figure 1), has anti-protozoan and antibacterial properties against anaerobic bacteria. The antimicrobial activity of this compound is due to reduction of the nitro group to a more reactive amine group that attacks microbial DNA, inhibiting further synthesis, and leading to degradation of the existing DNA., ${ }^{1,2}$

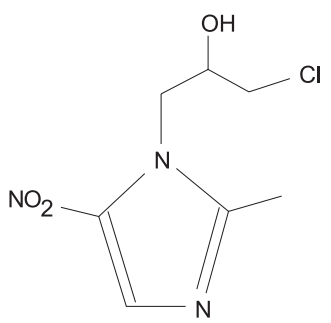

Figure 1. Chemical structure of ornidazole $\left(\mathrm{C}_{7} \mathrm{H}_{10} \mathrm{ClN}_{3} \mathrm{O}_{3}\right)$

Ornidazole has a molecular structure and pharmacological action similar to metronidazole, considered as the drug of choice among its class; however, it has some therapeutic advantages over metronidazole, for presenting longer half life, which is $12-14 \mathrm{~h}$ and $6-8 \mathrm{~h}$, respectively, resulting in the reduction of dosage frequency and duration of treatment in most clinical infections of major relevance, demonstrating its clinical importance as monotherapy to the population affected by these parasitosis and/or bacterial infections. ${ }^{3,4}$

Although the use of ornidazole tends to be published worldwide due to current studies that have successfully employed this substance in drug associations for the treatment of important high-cost chronic diseases, such as the treatment of Helicabacter pylori in peptic ulcers, some types of gastritis and stomach cancers; ${ }^{5}$ treatment of rheumatoid arthritis ${ }^{6}$ and in the prophylaxis of Crohn disease, where the latter is one of the major illnesses pertaining to the group of inflammatory bowel diseases (IBD). ${ }^{7}$

\footnotetext{
*e-mail: pedro.rolim@pq.cnpq.br
}

This drug was synthesized by Hoffmann-La-Roche in $1966 .{ }^{8}$ It is a white to light yellow, practically odorless, crystalline powder, practically insoluble in nonpolar solvents but its solubility is very high in moderately polar and highly polar solvents. ${ }^{3}$

There are no pharmacopoeic methods for the analysis of ornidazole tablets and there are no published works regarding the dissolution of this drug in the literature; now the published works regarding its determination through high performance liquid chromatography (HPLC) cover mainly the determination of this compound and/or its metabolites in biological fluids or associated to other drugs, mainly other nitroimidazole agents, ${ }^{9,10}$ where the pharmaceutical industry quality control routine, which must associate speed in analyses and reliability of results, is not applicable.

Dissolution test has emerged in the pharmaceutical field since 1960s as a very important tool to characterize drug product performance. ${ }^{11,12}$ Drug absorption from a solid dosage form after oral administration depends on the release of the drug substance from the drug product, drug dissolution or solubilization under physiological conditions, and permeability across the gastrointestinal tract. For this reason, the importance of dissolution tests and dissolution profile for the establishment of pharmaceutical equivalence as well as the importance in further bioequivalence studies must be highlighted. ${ }^{13}$ Besides, dissolution is a requirement for regulatory approval for product marketing and is a vital component of the overall quality control program. ${ }^{11,12}$

Dissolution testing is routinely used in Quality Control (QC) and Research \& Development (R\&D). The focus of dissolution testing in QC is batch consistency and detection of manufacturing deviations. The test should be designed to demonstrate that the dosage forms were manufactured according to specifications and all critical manufacturing steps result in a consistent product. In $R \& D$ the focus of dissolution testing is shifted to provide some predictive estimates of drug release with respect to in vivo performance of a drug product. ${ }^{14}$

In most cases the goals of QC versus R\&D approaches make it necessary to design two different dissolution protocols. An overdiscriminatory test might be suitable for QC purposes to detect even small production deviations. However, such a test is not desirable for the prediction of in vivo performance of drug product. Here dissolution testing should be a sensitive and a reliable predictor of bioavailability. ${ }^{15}$ 
The aim of the present work was the development of a new dissolution test for ornidazole coated tablets using a new high performance liquid chromatography (HPLC) method, to assay the drug substance, routinely in pharmaceutical companies' quality control.

\section{EXPERIMENTAL}

\section{Chemicals and instrumentation}

The following were used: a dissolution equipment (VK-7000 Varian, Palo Alto, USA), with automatic collector (VK-8000, Varian, Palo Alto, USA), high performance liquid chromatograph (Shimadzu, São Paulo, Brazil), with iodine arrangement detector, software Class-VP; ultrasound bath ultrasonic, model 2510 (Branson, Danbury, USA); model 2510; Milli-Q ${ }^{\circledR}$ system academic (Millipore, Massachusetts, USA). Raw material ornidazole based coated tablets $500 \mathrm{mg}$ (Zhejiang Supor Pharmaceuticals Co. Ltda, Zhejiang, China); ornidazole working standard (Zhejiang Supor Pharmaceuticals Co. Ltda, Zhejiang, China); methanol UV-HPLC grade (J.T Baker, Albany, NY); ultra-pure water (Milli-Q System, Massachusetts, USA); phosphoric acid (Merck, São Paulo, Brazil); filtering unit with a porosity of $0.45 \mu \mathrm{m}$ (Millipore, Massachusetts, USA); Shim-Pack ${ }^{\circledR}$ ODS (Shimadzu, São Paulo, Brazil) chromatograph column with packing $\mathrm{C}_{18}, 150 \times 4.6 \mathrm{~mm}$, particle diameter of $5 \mu \mathrm{m}$.

\section{Development of the HPLC assay method}

Aiming at the rational development of the analytical method, the influence of the oven temperature variation $\left(25\right.$ to $\left.40{ }^{\circ} \mathrm{C}\right)$, type of chromatographic columns $\mathrm{C}_{8}$ and $\mathrm{C}_{18}$, different methanol and ultrapure water mobile phase ratios $(45: 55, \mathrm{v} / \mathrm{v}$ and 20:80, v/v), besides the influence of ultra-pure water mobile phase acidification with $0.05 \%$ phosphoric acid were analyzed.

In order to assure good reproducibility of the method, the "column efficiency" must not be lower than 2000 theoretical plates, the tailing factor must be between 0.9 to 2 and the relative standard deviation of the replicate areas of the registered peaks must not be greater than $2 \%$. After development of the analytical method, uracil was injected, under the same established chromatographic conditions in order to check the "column dead" time and based on this information, to establish other important parameters for efficiency of the method. Uracil does not have affinity for the mobile phase and for the column, a determining factor to justify its use.

\section{Sample and standard solution preparation}

The sample volume collected from the dissolution tank was 1 $\mathrm{mL}$ with the immediate medium replacement and was diluted with methanol: ultra-pure water as the diluting solution $(45: 55, \mathrm{v} / \mathrm{v})$, so as to obtain the theoretical final concentration of $22.22 \mu \mathrm{g} / \mathrm{mL}$, similar to that of the standard, equivalent to $100 \%$ of the drug dissolved in the medium; the solution was filtered in a membrane with a porosity of $0.45 \mu \mathrm{m}$ and the sample was transferred to the vial.

\section{Chromatographic conditions}

Shim-Pack ${ }^{\circledR}$ ODS C18 chromatographic column, 150 x 4.6 mm, particle diameter of $5 \mu \mathrm{m}$; oven temperature $30{ }^{\circ} \mathrm{C}$; mobile phase flow $1.00 \mathrm{~mL} / \mathrm{min}$; wavelength $318 \mathrm{~nm}$; mobile phase methanol: ultra-pure water acidified at $0.05 \%$ phosphoric acid $(45: 55, \mathrm{v} / \mathrm{v})$; sample dilution with methanol: Milli- ${ }^{\circledR}$ water $(45: 55, \mathrm{v} / \mathrm{v})$; final reading sample concentration of the $22.22 \mu \mathrm{g} / \mathrm{mL}$; injection volume $20 \mathrm{uL}$ and run time $5 \mathrm{~min}$.

\section{Validation of the method}

After the development of the method, the following parameters were evaluated: linearity, precision, accuracy, specificity, limits of detection/quantification and robustness.

\section{Linearity}

This assay was performed with linear regression analysis through the least square method of the mean points of three authentic curves with seven points in the concentrations of 1.00, 6.00, 11.00, 16.00, $20.00,30.00$ and $40.00 \mu \mathrm{g} / \mathrm{mL}$ of ornidazole working standard. The coefficient of correlation was obtained from the mean of three curves.

\section{Precision}

Precision was determined through repeatability and intermediate precision methods. Repeatability was determined through analysis of individual samples in sextuplicate. Intermediate precision was determined in two days by two different analysts.

\section{Accuracy}

Three batches of tablets were obtained with the percentage of fixed excipients, varying only the concentration of the active ingredient in 50, 100 and $150 \%$ of ornidazole. Extraction of the active ingredient during preparation was carried out as described in the item "sample preparation". Next, each sample was analyzed in triplicate.

\section{Specificity}

A placebo of the ornidazole tablet was analyzed through the described technique.

\section{Limit of detection (LOD) and limit of quantification (LOQ)}

To carry out LOD and LOQ, the standard deviation of the straight line in relation to the absorbance of the first concentration level (1.00 $\mu \mathrm{g} / \mathrm{mL}$ ) of ornidazole was considered in the three calibration curves and their angular coefficient.

\section{Robustness}

The assay was determined from the variation on the following parameters: sonication time of the solutions (8, 10 and $12 \mathrm{~min})$, oven temperature $\left(29,30\right.$ and $\left.31^{\circ} \mathrm{C}\right)$, mobile phase flow $(0.98,1.00$ and $1.02 \mathrm{~mL} / \mathrm{min}$ ) and chromatographic column (Shim-Pack ${ }^{\circledR}$ ODS C $_{18}$; 150 x 4.6 mm; 5 m: Batch: $\mathrm{M}^{\circ} 4157111$ and Batch: $\left.\mathrm{M}^{\circ} 4157010\right)$. Sample analyses in quadruplicate were performed for all robustness parameters.

\section{Development of the dissolution analytical method}

The following parameters were evaluated: dissolution medium (distilled water, $0.10 \mathrm{M}$ hydrochloric acid, potassium phosphate buffer ( $\mathrm{pH} 7.30$ ) and sodium acetate buffer ( $\mathrm{pH} 4.30$ ), apparatus 1 (basket) at rotation speeds of 50 and $100 \mathrm{rpm}$, and apparatus 2 (paddle) at a rotation speed 50, 75 and $100 \mathrm{rpm}$, where these rotation speeds were preset for each apparatus according to U.S. Pharmacopeia (USP) $31^{16}$ and the Food and Drug Administration ${ }^{17}$ (FDA) Guide. The dissolution medium was heated at $40{ }^{\circ} \mathrm{C}$ and sonicated, the volume used in the tanks was $900 \mathrm{~mL}$, and stabilization of solution temperature at 37 $\pm 0.50{ }^{\circ} \mathrm{C}$ and the aliquots were withdrawn at $5,10,15,20$ and 30 min. Besides having been analyzed drug stability in the dissolution medium for a period of $24 \mathrm{~h}$ and the influence of sample filtration.

\section{Sample preparation}

One tablet was added to each dissolution tank and the test was performed; samples were collected at the scheduled time(s); the collected sample volume was $1 \mathrm{~mL}$ with immediate medium replacement. 


\section{Validation}

The dissolution method was developed and subsequently validated complying with the specific chapter of USP $31^{16}$ and the FDA guide $;^{17}$ this method is classified according to its purpose as performance test, pertaining to category 3 , presenting as requirement the Precision/Repeatability assay for validation of the method.

\section{RESULTS AND DISCUSSION}

\section{Development of the HPLC dosing method}

The high selectivity and efficiency of the chromatographic column employed is proven through the obtained theoretical plate results, which is approximately 3472.9 ; the adequate definition and symmetry of the peak is proven through the obtained tailing factor result, which is approximately 1.14 and the capacity factor, calculated from data obtained through uracil analysis, resulted in an approximate value of 5.67 .

The results obtained with the validation of this method are described in Table 1. It was chosen to work with the first concentration level of $1.00 \mu \mathrm{g} / \mathrm{mL}$ of ornidazole for being representative of $\pm 5 \%$ of the drug dissolved in the dissolution medium, presenting the method to be capable of detecting, within its linearity range, from 5 to $150 \%$ of the content of an ornidazole tablet in the dissolution medium.

Table 1. Results of the quantification method validation

\begin{tabular}{ccc}
\hline Method & Parameters & Results \\
\hline & Linearity range $(\mu \mathrm{g} / \mathrm{mL})$ & $1.00-40.00$ \\
$\lambda(\mathrm{nm})$ & 318 \\
Slope & $45857.94 \pm 442.85$ \\
Intercept & $12292.30 \pm 3882.26$ \\
$\mathrm{R}^{2}$ & 0.99998 \\
HPLC & Repeatability $(\%)$ & $100.07 \pm 1.22$ \\
& DPR $(\%)$ & 1.19 \\
Specificity & 0.00 \\
DL $(\mu \mathrm{g} / \mathrm{mL})$ & 0.21 \\
QL $(\mu \mathrm{g} / \mathrm{mL})$ & 0.69 \\
Accuracy $(50 \%)$ & 49.20 \\
Accuracy $(100 \%)$ & 100.38 \\
Accuracy $(150 \%)$ & 149.32 \\
\hline
\end{tabular}

\section{Precision}

Intermediate precision

It was demonstrated through the ANOVA One-Way test that there was no statistically significant difference with a $95 \%$ confidence level, presenting for the variation between days with a calculated F of 1.3687 and tabulated F of 4.7570 and for the variation between analysts a calculated F of 0.6808 and tabulated F of 5.1432 .

\section{Robustness}

Samples were analyzed in quadruplicate for each analyzed variation parameter: Batch of the chromatographic column, oven temperature, mobile phase flow and sonication time of the solution. All samples used in the robustness studies presented a mean concentration of $22.22 \mu \mathrm{g} / \mathrm{mL}$. The results obtained from the analysis of these parameters are shown in Table 2.
Table 2. Mean of the dissolution efficiency (ED) of the dissolution medium parameter at the $15 \mathrm{~min}$ time point

\begin{tabular}{lccc}
\hline Water & HCl 0.1 M & Acetate $\mathrm{pH} \mathrm{4.3}$ & Phosphate $\mathrm{pH} \mathrm{7.3}$ \\
\hline 71.28 & 79.66 & 71.38 & 75.16 \\
\hline
\end{tabular}

\section{Development of the dissolution analytical method}

In the development of the dissolution method, the influence of the dissolution medium on the drug release profile was first analyzed; the nature of the media involved are within the physiologic $\mathrm{pH}$, besides complying with the Sink condition. ${ }^{18}$ It was chosen to work with the dissolution profile of 5 collection points $(5 ; 10 ; 15 ; 20$ and $30 \mathrm{~min}$ ), since it allows better view of the influence of the dissolution medium. For analysis of the influence of this parameter, the use of apparatus 2 (paddle) with rotation speed of $100 \mathrm{rpm}$ was standardized. ${ }^{13}$ The comparison between dissolution profiles was carried out through dissolution efficiency (DE) parameter at the collection point of $15 \mathrm{~min}$, for being considered a discriminative point, where this is defined as the area under the dissolution curve up to a time $t$, expressed as the percentage of the rectangular area that would correspond to $100 \%$ of the dissolution at the same time.

It can be noticed that there is a higher standard deviation among the first test points, due to the variations inherent to the object itself under study, the tablet, and its technological process, compression and coating, which reflect on the test results an expected variability, without having any direct relation to the influence of the dissolution medium (Figure 2). In this case, the influence of the dissolution medium was analyzed through the calculation of dissolution efficiency at the time of $15 \mathrm{~min}$ (Table 2) in a discriminative way, demonstrating greater efficiency of the medium $0.1 \mathrm{M} \mathrm{HCl}$, enabling the choice of the most suitable medium. When compared to the second best medium, phosphate buffer $\mathrm{pH} 7.3,0.1 \mathrm{M} \mathrm{HCl}$ showed to be better and different when treated through a statistical test, Student's $t$ test with $5 \%$ significance level. After the collection point of $15 \mathrm{~min}$, there are no more significant differences in the media when compared through statistical test Student's t test with 5\% significance level. This way, we can show that the $\mathrm{pH}$ of the medium does not influence in the drug dissolution.

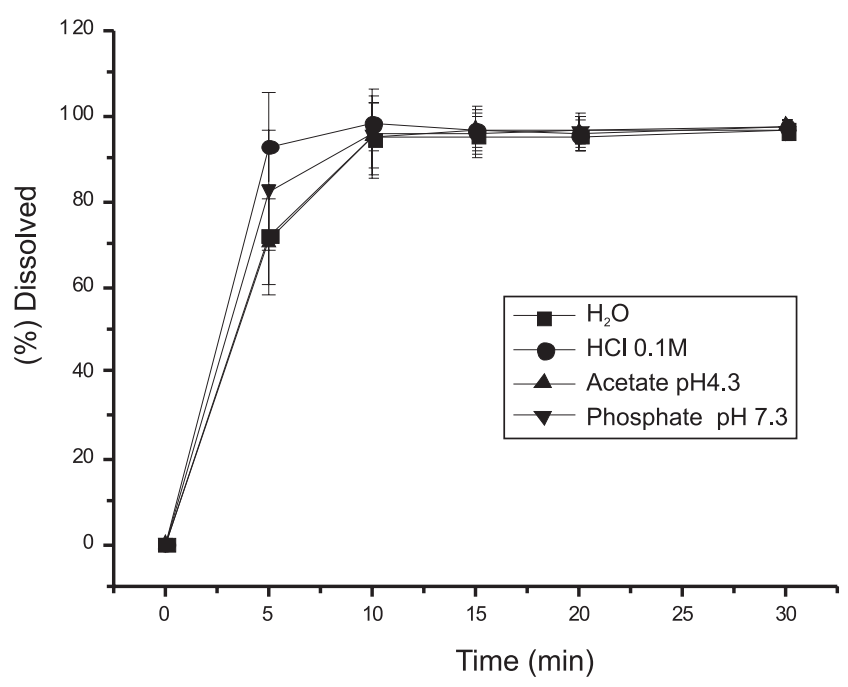

Figure 2. Dissolution profile of ornidazole in different dissolution mediums

With the selected dissolution medium, the influence of the rotation speed and the type of apparatus were checked; it can be proven that apparatuses 1 and 2, at a rotation speed of $50 \mathrm{rpm}$, presented a lower 
dissolution percentage when compared to the other rotation speeds, which were excluded from the analysis (Figure 3). In the analysis of apparatuses 1 and 2 at a rotation speed of $100 \mathrm{rpm}$, apparatus 2 (paddle) showed to be more efficient, justifying its selection, besides being more commonly employed in the analysis of tablet dosage form according to official compendia. Lastly, the results obtained from apparatus 2 at speeds of 75 e $100 \mathrm{rpm}$ were compared, where they were statistically different according to Student's t Test with 5\% significance level, demonstrating greater dissolution efficiency at a stirring speed of $75 \mathrm{rpm}$ (Figure 3 and Table 3).

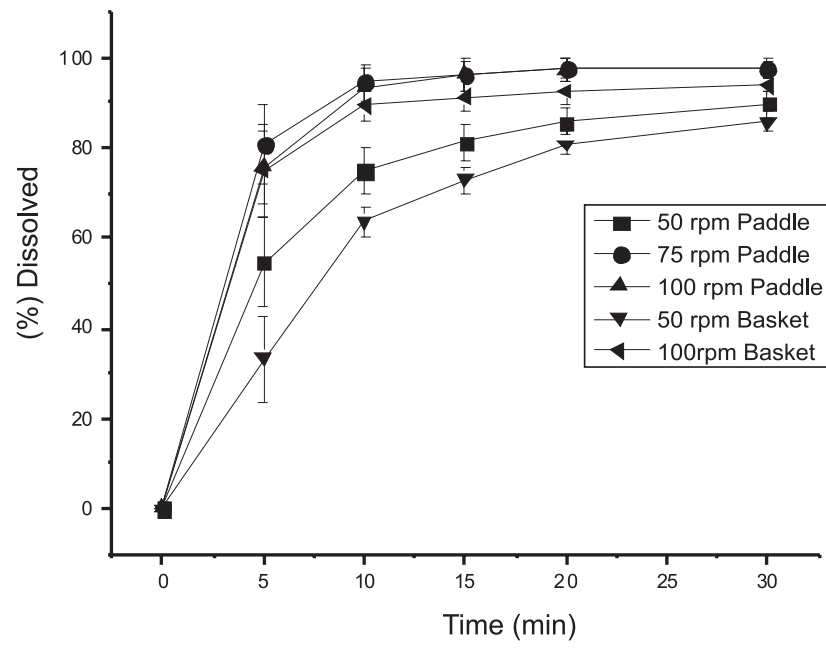

Figure 3. Dissolution profile of ornidazole with different apparatus and stirring

Table 3. Dissolution efficiency mean of the stirring parameters and apparatus at the $15 \mathrm{~min}$ time point

\begin{tabular}{lcccc}
\hline DE $(\%)$ & DE $(\%)$ & DE $(\%)$ & DE $(\%)$ & DE $(\%)$ \\
$50 \mathrm{rpm}$ & $75 \mathrm{rpm}$ & $100 \mathrm{rpm}$ & $50 \mathrm{rpm}$ & $100 \mathrm{rpm}$ \\
Paddle & Paddle & Paddle & Basket & Basket \\
\hline 56.71 & 74.39 & 72.30 & 44.40 & 69.93
\end{tabular}

With the defined dissolution medium, apparatus and rotation speed, the influence of medium filtration in sampling was analyzed; this analysis was carried out only for the time of $30 \mathrm{~min}$. The statistical study Student T test was also applied, which showed that the calculated $\mathrm{t}$ of 0.37 was lower than the tabulated $\mathrm{t} 2.14$, with $5 \%$ significance level, proving that there was no significant different between the analyzed means and the filtered and non-filtered samples.

With the $24 \mathrm{~h}$ stability study of the sample in the dissolution medium $(0.1 \mathrm{M} \mathrm{HCl})$, it can be shown that the sample is stable in this medium for that period. The applied statistics study was Student T Test, which demonstrated that the calculated $t$ of 1.87 was lower than the tabulated $t$ of 2.18 , with $5 \%$ significance level, proving that there was no significant difference among the analyzed means.

After the development of the analytical method carried out through the dissolution profile, the value of $85 \%$ of the dissolved drug in up to $30 \mathrm{~min}$ ( $\mathrm{T} \geq 85 \%$ in $30 \mathrm{~min}$ ) was defined as the specification for this method, where this is a pharmacopoeic specification for products of immediate release.
Precision was evaluated through repeatability analysis, through 8 different sample collections within the specified time of $30 \mathrm{~min}$. The statistical treatment of the data resulted in a mean on $95.90 \%$, standard deviation of $1.78 \%$, and coefficient of variation of $1.86 \%$. The method can be considered precise, since the coefficient of variation $(\mathrm{CV})$ is below the recommended, where this $\mathrm{CV}$ is up to $10 \%$.

\section{CONCLUSIONS}

The present work reports the development and the validation of a new dissolution test for ornidazole coated tablets, based on a new HPLC-RP method of analysis. Both the HPLC-RP analysis and dissolution test were fully validated through resulting adequate for routine Quality Control of ornidazole tablet, since the methods test of this medicine is not listed in any pharmacopoeia and there is no dissolution test for tablets reported in literature.

\section{REFERENCES}

1. Özkan, A. S.; Senturk, Z.; Ind. J. Pharm. 1997, 157, 137.

2. Wang, M. H.; Tan, Z. C.; Sun, X. H.; Xu, F.; Liu, Y. F.; Sun, L. X.; Zhang, T.; Thermochim. Acta 2004, 414, 25.

3. Singh, P.; Mittal, R.; Sharma, G. C.; Singh, S.; Singh, A.; Profiles of Drug Substances, Excipients, and Related Methodology 2003, 30, 123.

4. Rossignol, J. F.; Maisonneuve, H.; Cho, Y. W.; Int. J. Clin. Pharmacol. Ther. Toxicol. 1984, 22, 63.

5. Díte, P.; Kunovská, M.; Pulgertová, D.; Woznice, V.; Petrtýl, J.; Hůlek, P.; Pásková, J.; Dostalík, Z.; Novotný, I.; Procházka, V.; Hegyi, P.; Zelenková, J.; Samek, M.; Králová, Z.; Vyhnálek, P.; Matějovič, F.; Weinberg, J.; Kyzeková, J.; Purkyně. J. E.; Vnitrní lékarství 2002, 48, 976.

6. Ogrendik, M.; Rheumatol. Int. 2006, 26, 1132.

7. Faubion, W. A.; Bousvaros Junior, A.; Clin. Gastroenterol. Hepatol. 2006, 4, 1199.

8. Hoffer, M.; Grunberg, E.; J. Med. Chem. 1974, 17, 1019.

9. Manjunath, S.; Ravi, K. U. M.; Raju, S. A.; Asian J. Chem. 2000, 12, 797.

10. Xu, J. P.; Li, J.; Zhang, H.; Zhang, M.; Pharm. Care Res. 2006, 6, 136.

11. Garcia, C. V.; Paim, C. S.; Steppe, M.; Schapoval, E. E. S.; J. Pharm. Biomed. Anal. 2006, 41, 833.

12. Dumont, L. M.; Berry, M. R.; Nickerson, B.; J. Pharm. Biomed. Anal. 2007, 44, 79 .

13. Fernandes, C.; Junqueira, R. G.; Campos, L. M. M.; Pianetti, G. A.; J. Pharm. Biomed. Anal. 2006, 42, 601.

14. Azarmi, S.; Roa, W.; Löbenberg, R.; Int. J. Pharm. 2007, 328, 12.

15. Siewert, M.; Dressman, J.; Brown, C.; Shah, V.; Williams, R.; AAPS Pharm. Sci. Tech. 2003, 4, 1.

16. Soares, M. F. R.; Soares-Sobrinho, J. L.; Grangeiro-Júnior, S.; Silva, K. E. R.; Rolim-Neto, P. J.; Lat. Am. J. Pharm. 2008, 27, 688.

17. The United States Pharmacopeial Convention; USP 31, Rockville, USA, 2008, p. 194-195.

18. FDA; Dissolution Testing of Immediate Release Solid Oral Dosage Forms, Guidance for Industry, Rockville, USA, 1997.

19. Hoti, E.; Censi, R.; Ricciutelli, M.; Malaj, L.; Barboni, L.; Martelli, S.; Valleri, M.; Di Martino, P.; J. Pharm. Biomed. Anal. 2008, 47, 422. 